\title{
A CORE/SHELL APPROACH TO DOPANT INCORPORATION AND SHAPE CONTROL IN COLLOIDAL ZINC OXIDE NANORODS
}

\author{
Saahil Mehra ${ }^{1}$, Amy Bergerud ${ }^{2}$, Delia J. Milliron ${ }^{3,4}$, Emory M. Chan ${ }^{3}$, Alberto Salleo ${ }^{1, *}$ \\ 1. Department of Materials Science \& Engineering, Stanford University, Stanford CA 94305 \\ 2. Department of Materials Science \& Engineering, University of California Berkeley, Berkeley CA 94720 \\ 3. The Molecular Foundry, Lawrence Berkeley National Laboratory, Berkeley, CA 94720 \\ 4. McKetta Department of Chemical Engineering, University of Texas at Austin, Austin, TX 78712 \\ *Corresponding Author: asalleo@stanford.edu
}

\section{Supporting Information (SI)}



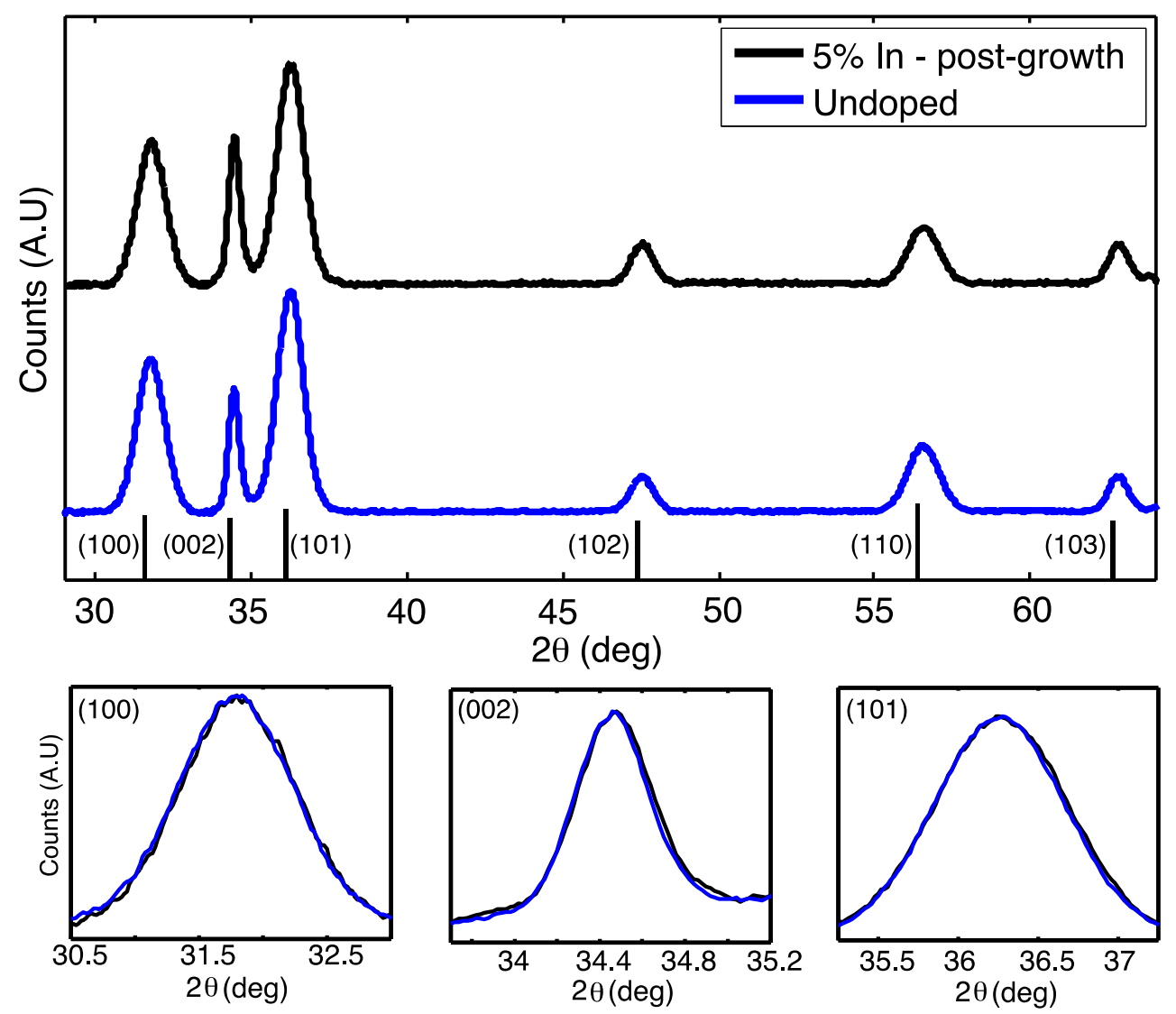

Figure S1: X-Ray diffraction data of undoped and in-situ post-growth In-doped $\mathrm{ZnO}$ nanorods. Normalized data is shown for the (100), (002) and (101) peaks, indicating similar lattice spacing and imply that the dopants are not incorporated in large amounts into the crystal structure using this doping strategy. Black lines indicate positions of wurtzite $\mathrm{ZnO}$ peaks (JCPDS \#36-1451). 


\begin{tabular}{|c|c|c|c|}
\hline Reference & $\begin{array}{c}\text { Doped Injection Set } \\
\text { Concentration } \\
\text { (mol\%) }\end{array}$ & $\begin{array}{c}\text { Dopant present } \\
\text { in synthesis } \\
\text { (mol \%) }\end{array}$ & $\begin{array}{c}\text { Nominal } \\
\text { doping } \\
\text { concentration } \\
\text { [ICP] } \\
\text { (mol\%) }\end{array}$ \\
\hline $\begin{array}{c}\text { Figure 1A } \\
\text { doping throughout }\end{array}$ & In (5\%) & 4.2 & 2.9 \\
\hline $\begin{array}{c}\text { Figure 1B } \\
\text { in-situ post-growth }\end{array}$ & In (5\%) & 2.1 & 0.6 \\
\hline $\begin{array}{c}\text { Figure 1C } \\
\text { Doping after seeds form }\end{array}$ & In (3\%) & 0.9 & 0.4 \\
\hline $\begin{array}{c}\text { Figure 1D } \\
\text { 'Core/Shell' type doping }\end{array}$ & In (3\%) & 1.27 & 1.3 \\
\hline $\begin{array}{c}\text { Figure 1C } \\
\text { Doping after seeds form }\end{array}$ & Al (3\%) & 0.9 & 0.9 \\
\hline $\begin{array}{c}\text { Figure 1D } \\
\text { 'Core/Shell' type doping }\end{array}$ & Al (3\%) & 1.27 & 1.5 \\
\hline
\end{tabular}

Table S1: Dopant concentration for different syntheses as measured by ICP 


\section{Estimation of Free Carrier Concentrations:}

The free carrier concentration, $n$, was estimated to make an order of magnitude estimate of different doping levels using the FTIR data obtained for each sample and the equation for the LSPR peak position for a spherical nanoparticle,

$$
n=\frac{m_{e 0}\left(+2_{m}\right)^{2}}{e^{2}}
$$

where $\omega$ is the LSPR frequency, e is the electron charge, $1.6 \times 10^{-19} \mathrm{C}, \mathrm{m}_{\mathrm{e}}$ is the electron effective mass ( 0.25 times the free electron mass $-9.11 \times 10^{-31} \mathrm{~kg}$ - for $\left.\mathrm{ZnO}\right), \varepsilon_{0}$ is the vacuum permittivity, $8.854 \times 10^{-12} \mathrm{~F} \cdot \mathrm{m}^{-1}, \varepsilon_{\infty}$ is the high-frequency dielectric constant (3.71 for $\mathrm{ZnO}$ ), \& $\varepsilon_{\mathrm{m}}$ is the dielectric constant of the medium (2.5 for tetrachloroethylene, TCE).

The dopant activation fraction was subsequently calculated by assuming all free carriers come from activated dopants and converting the estimated free carrier concentration to a dopant activation fraction, $x_{d o p}$, using the following relation

$$
n=\frac{N_{A V}}{M W_{Z n O}} \quad{ }_{Z n O} x_{d o p} .
$$




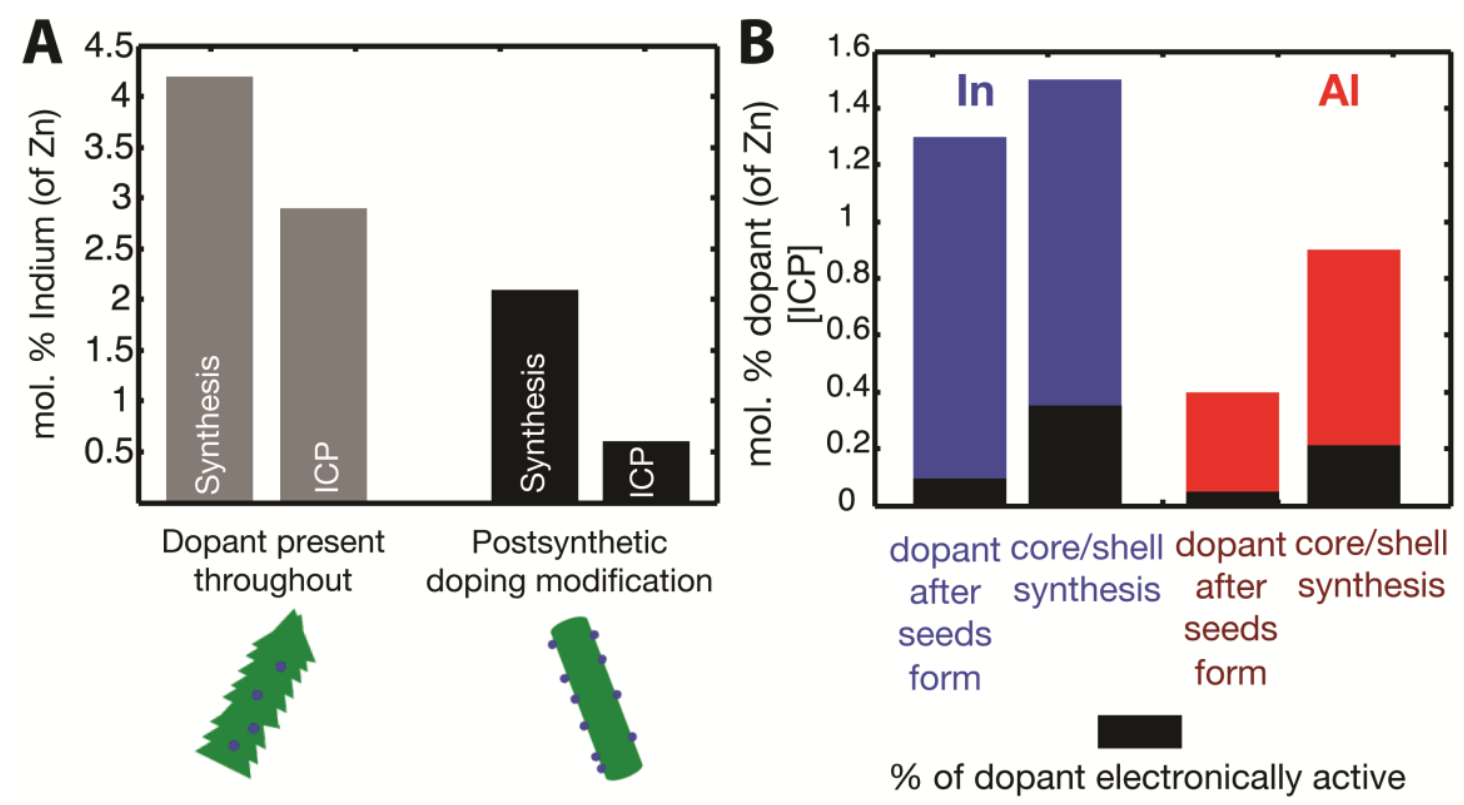

Figure S2: Comparison of dopant incorporation efficiencies for each of the doping cases presented in the manuscript. (A) Nominal amounts of dopant in synthesis compared to amount measured by ICP for the limiting cases (B) Nanorod dopant concentration measured by ICP for the Al- and In-doped cases. The black area indicates the amount of activated dopant estimated by the general position of the LSPR peak observed by FTIR for each sample. 

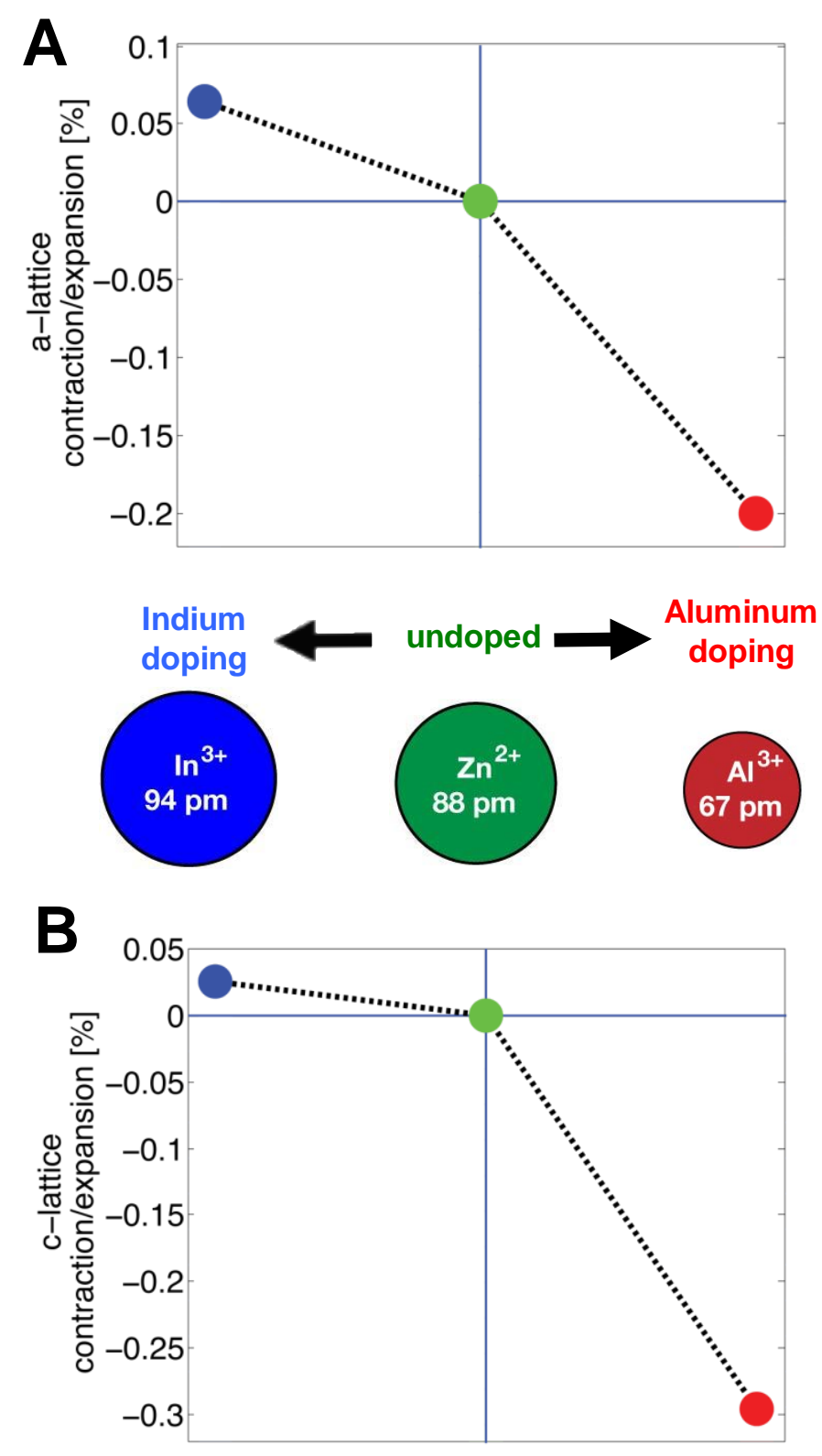

Figure S3: Lattice parameters calculated for the a-parameter (A) and c-parameter (B) based on indium and aluminum doped nanorod XRD data in Figure 3 of the manuscript. The data show trends consistent with dopant cation size - lattice contraction relative to undoped $\mathrm{ZnO}$ is observed with $\mathrm{Al}$ doping, and lattice expansion relative to undoped $\mathrm{ZnO}$ is observed with In doping. Parameters were estimated using Rietveld Refinement and MAUD software. ${ }^{1}$

\footnotetext{
${ }^{1}$ L. Lutterotti, Total pattern fitting for the combined size-strain-stress-texture determination in thin film diffraction, Nuclear Inst. and Methods in Physics Research, B, 268, 334-340, 2010
} 


\begin{tabular}{|c|c|c|}
\hline Reference & $\begin{array}{l}\text { Doped Injection } \\
\text { Set Concentration } \\
(\mathrm{mol} \%)\end{array}$ & $\mathrm{E}_{\mathrm{G}}[\mathrm{eV}]$ \\
\hline $\begin{array}{c}\text { Figure 1A } \\
\text { doping throughout synthesis }\end{array}$ & In $(5 \%)$ & 3.32 \\
\hline $\begin{array}{c}\text { Figure 1B } \\
\text { in-situ post-growth doping }\end{array}$ & $\operatorname{In}(5 \%)$ & 3.28 \\
\hline $\begin{array}{c}\text { Figure } 1 \mathrm{C} \\
\text { Doping after seeds form }\end{array}$ & In $(3 \%)$ & 3.31 \\
\hline $\begin{array}{l}\text { Figure 1D } \\
\text { 'Core/Shell' type doping }\end{array}$ & In $(3 \%)$ & 3.31 \\
\hline $\begin{array}{c}\text { Figure } 1 \mathrm{C} \\
\text { Doping after seeds form }\end{array}$ & $\mathrm{Al}(3 \%)$ & 3.31 \\
\hline $\begin{array}{l}\text { Figure 1D } \\
\text { 'Core/Shell' type doping }\end{array}$ & $\mathrm{Al}(3 \%)$ & 3.32 \\
\hline $\begin{array}{c}\text { Figure } 1 \mathrm{C} \\
\text { Doping after seeds form }\end{array}$ & $\operatorname{In}(5 \%)$ & 3.30 \\
\hline $\begin{array}{c}\text { Figure 1D } \\
\text { 'Core/Shell' type doping }\end{array}$ & $\operatorname{In}(5 \%)$ & 3.32 \\
\hline $\begin{array}{c}\text { Figure } 1 \mathrm{C} \\
\text { Doping after seeds form }\end{array}$ & $\mathrm{Al}(5 \%)$ & 3.33 \\
\hline $\begin{array}{c}\text { Figure 1D } \\
\text { 'Core/Shell' type doping }\end{array}$ & $\mathrm{Al}(5 \%)$ & 3.33 \\
\hline Undoped $\mathrm{ZnO}$ & $n / a$ & 3.28 \\
\hline
\end{tabular}

Table S2: Optical band gap for different dopant levels/synthetic approaches calculated using Tauc's method (extrapolation of the linear absorption onset to 0 ). 

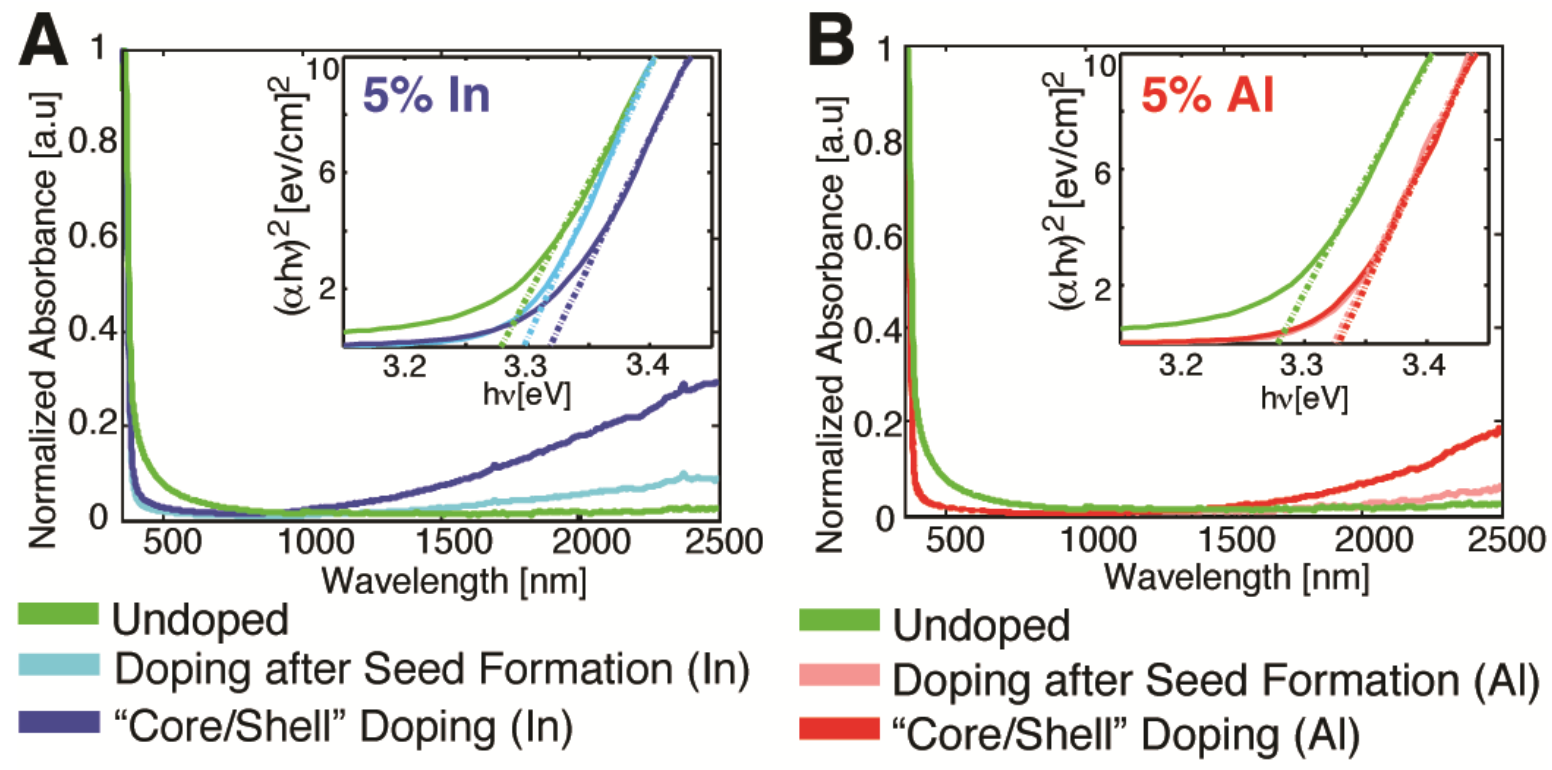

Figure S4: Optical characterization of doped zinc oxide nanorods. Plots show UV-vis absorbance spectra, insets show band gap estimation from the Burstein-Moss effect. Doping after seeds form and 'Core/Shell' type doping series with 5\% In doping (A), 5\% Al doping (B) All spectra are normalized to undoped $\mathrm{ZnO}$ absorption (green). 

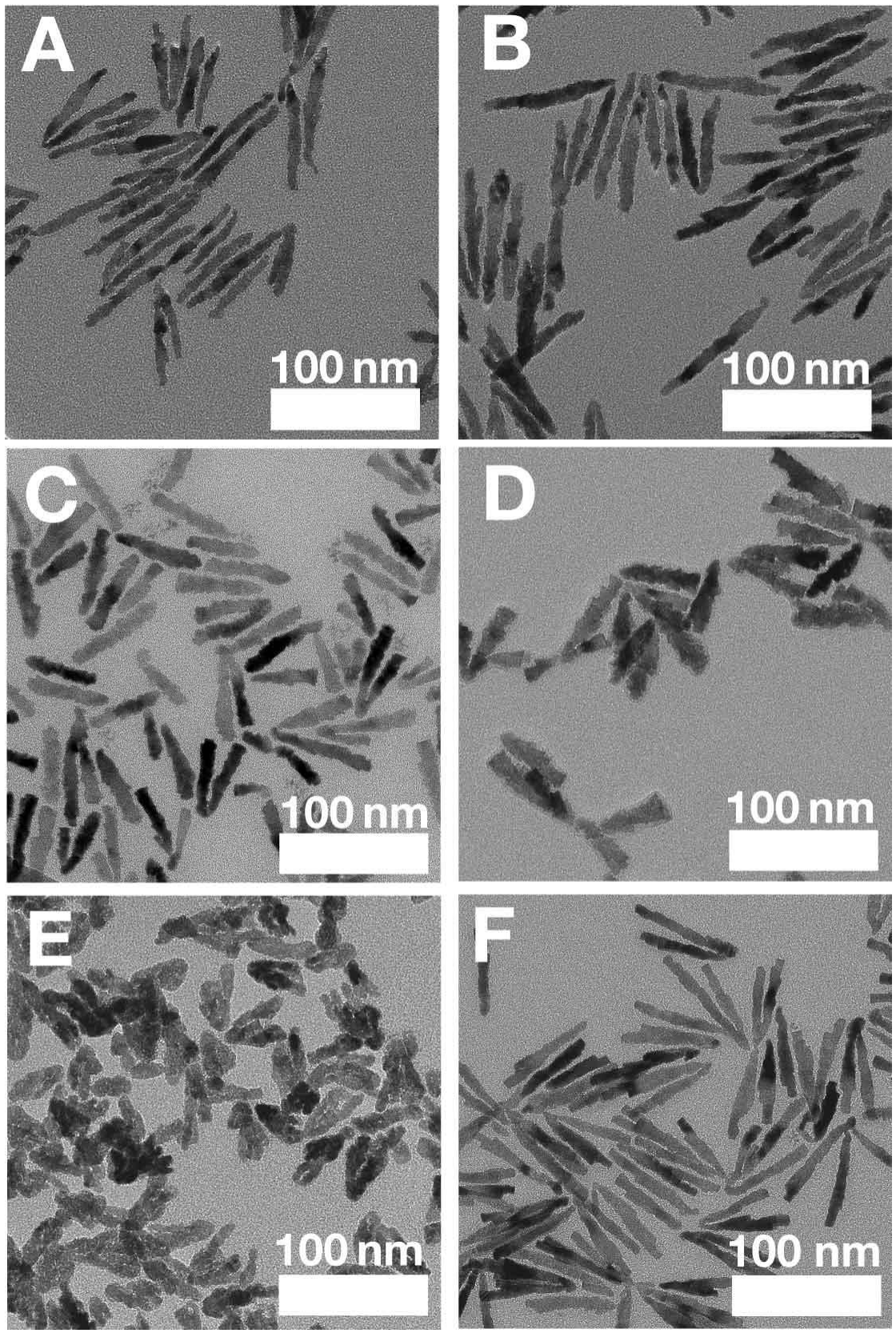

Figure S5: TEM Images of $\mathrm{ZnO}$ nanorods doped with different strategies at higher doping concentrations. 5\% $\mathrm{Al}$ - doping after seeds form (A), 5\% $\mathrm{Al}$ - 'core/shell' type doping (B), 5\% In - doping after seeds form (C), 5\% Al - 'core/shell' type doping (D), $5 \%$ In - dopant throughout (E), 5\% In - in-situ post-growth doping (F) 


\section{Discussion on Surface Indium Concentrations}

XPS analysis was performed using CasaXPS software. The surface concentrations of Zn and In can be inferred from the area ratios of the $\mathrm{Zn} / \mathrm{In}$ peaks obtained in the highresolution spectra shown in Figure 4. Peak fitting was performed using linear baseline corrections and peak area constraints due to degeneracy. Using the area ratios and the relative sensitivity factors (RSF), the measured peak areas are scaled to represent surface concentrations of In/Zn. For the surface concentration calculations, the RSF used for $\mathrm{Zn}$ (2p 3/2) was 3.726, and the RSF used for In (3d 5/2) was 4.359. Both RSFs were obtained using the Physical Electronics XPS Handbook provided for the PHI5400 XPS equipment.

The adjusted peak area calculation for each element was performed as follows: Adjusted Peak Area = Measured Peak Area/RSF. 